\title{
Incidence of adult traumatic spinal cord injury in Saint Petersburg, Russia
}

\author{
Lyudmilla Mirzaeva $^{1} \cdot$ Nils Erik Gilhus ${ }^{2,3} \cdot$ Sergey Lobzin ${ }^{1} \cdot$ Tiina Rekand $\mathbb{C}^{3,4}$
}

Received: 25 June 2018 / Revised: 21 February 2019 / Accepted: 21 February 2019 / Published online: 6 March 2019

(c) International Spinal Cord Society 2019

\begin{abstract}
Study design Retrospective population-based cohort study.

Objectives To characterise the epidemiology of traumatic spinal cord injury (TSCI) among the inhabitants of Saint Petersburg, Russia.

Setting All hospitals in Saint Petersburg.

Methods Charts for all individuals admitted to city hospitals from 1st January 12012 to 31st December 2016 with acute TSCI were reviewed. Incidence rates were calculated for the whole period and for each year separately. Gender-specific and age-specific incidence rates were calculated, and epidemiological characteristics and possible risk factors were analysed.

Results A total of 361 people were identified. The average annual incidence rate was 17.6 per million, varying from 21.2 (2013) to 13.6 (2016), and 70.9\% were men. Mean age at injury was 42.1 years. Injuries from falls represented $49.8 \%$ of cases, and motor vehicle accidents $18.9 \%$. The male:female ratio in the low-falls group was $1.2: 1$, and among the elderly patients, it was 0.5:1. Lesions at the cervical level were involved in $49.3 \%$, thoracic in $24.7 \%$, and lumbar/sacral in $23.5 \%$. TSCI was complete in $16.9 \%$. Concomitant injuries occurred in $47.2 \%$ of cases, and traumatic brain injuries in $37.7 \%$.

Conclusion TSCI incidence decreased during the observation period and was 2.4 times more common among men than women. In half of the cases, injuries involved the cervical level, and a fall was the most frequent injury cause. Elderly women more often had falls from a low height than men. Multiple injuries—most frequently traumatic brain injuries-were common.
\end{abstract}

\section{Introduction}

The annual incidence of traumatic spinal cord injury (TSCI) varies considerably worldwide [1], from 10 to 83 per million inhabitants according to population-based and hospitalbased epidemiologic data. Most countries report an annual

Tiina Rekand

tiina.rekand@helse-bergen.no

1 Department of Neurology, North-Western State Medical University, Saint Petersburg, Russia

2 Department of Clinical Medicine, University of Bergen, Bergen, Norway

3 Department of Neurology, Haukeland University Hospital, Bergen, Norway

4 Institute for Clinical Neuroscience and Physiology, The Sahlgrenska Academy, University of Gothenburg, Gothenburg, Sweden incidence of 15-30 per million [2-6], and prevalence ranges from 236 per million in India to 1800 per million in the United States [1]. Epidemiology varies among regions because of cultural, economic, and social factors [7-11]. TSCI epidemiology is well documented in Western Europe, North America, and Australia, where countries have implemented TSCI registries as a system for collecting patient information that facilitates comparison of epidemiological characteristics across time periods. TSCI data from Russia and Eastern Europe, however, are limited and were published decades ago [12-14].

We have studied a population-based cohort of adults with TSCI in Saint Petersburg, Russia, which is an urban area situated in the European part of the country. To ensure a truly population-based analysis, all hospitals in Saint Petersburg were included. The results reflect TSCI incidence and will help to identify causes and possible lifestylerelated risk factors for TSCI in this region. 


\section{Methods}

\section{Study population and social and geographical characteristics of Saint Petersburg}

The area of Saint Petersburg is $1439 \mathrm{~km}^{2}$. The registered number of inhabitants was collected from the Administration of the Federal State Statistics Service for Saint Petersburg and the Leningrad Region [15]. The estimated adult population (age $\geq 18$ years) was 4,267,500 in 2012 and $4,400,500$ in 2016.

\section{Inclusion criteria}

According to the summary reports routinely presented to the Health Care Committee, hospitals that reported having hospitalised persons with ICD-10 codes suggestive of TSCI were selected. Those hospitals in Saint Petersburg were included and scrutinised according to the inclusion/exclusion criteria for this retrospective epidemiological cohort study. All patients with ICD-10 codes S14 (S14.0, S14.1), S24 (S24.0, S24.1), and S34 (S34.0, S34.1, S34.3) were included. To avoid misclassification, the following codes were also covered in the search: S12 (S12.0, S12.1, S12.2, S12.7), S13 (S13.0, S13.1, S13.2, S13.4), S22 (S22.0), S23 (S23.0, S23.4), S32 (S32.0), S33 (S33.0, S33.1), G82, T06 (T06.0, T06.1), T08, T09.3, and T91 (T91.1, T91.3). The statistics department of each hospital assisted in identifying records with these ICD-10 codes.

A total of 1517 patients with these ICD-10 diagnoses were identified among the 13 hospitals in the period from 1st January 2012 to 31st December 2016. Patient charts for January-March 2017 (76 charts) were also requested, to capture any cases presenting at the end of 2016. The first author of this paper analysed all patient charts to confirm the diagnosis according to the definition of acute TSCI. TSCI was defined as an acute traumatic lesion of the spinal cord with varying degrees of motor and/or sensory deficit or paralysis $[12,16]$. Injury of the cauda equina was included.

The study included adult patients aged 18 years or older, officially registered as residents of Saint Petersburg. Only persons with permanent residence in Saint Petersburg and migrants officially registered as residents were included in the study.

\section{Exclusion criteria}

Persons who died in the prehospital phase were not included in the study, whereas those who died in a hospital were included. Patients with vertebral fractures without spinal cord injury, isolated injuries of nerve roots, or only autonomic nervous system manifestations were excluded. A considerable but unknown number of persons with a permanent address in other areas of Russia live undocumented in Saint Petersburg, as do tourists and migrant workers. Individuals from these groups were not included.

\section{Chart data}

The following information was extracted from the charts: sex, age, exact time of injury, employment before TSCI, severity and level of TSCI, cause of TSCI, alcohol and drug consumption at the time of injury, and concomitant injuries. The International Standard for Neurological Classification of Spinal Cord Injury was used for classification of TSCI $[17,18]$. The neurological level of injury and severity of TSCI were assessed, and groups were defined according to the latest recommendations [18]. In cases of multiple TSCI, the case was classified by the highest level. Clinicians scored cases based on the American Spinal Injury Association Impairment Scale (AIS).

\section{Statistical analyses}

The data were collected on a Microsoft Excel spreadsheet, and statistical analysis was performed using STATISTICA10. Mean values with standard deviations (SDs) and median values with interquartile ranges (IQRs) were calculated. Because of the descriptive nature of the study, no inferential statistics was used. Incidences were calculated based on official statistical population data [15].

\section{Results}

In total, 1517 charts were reviewed. Among these, 361 patients had a confirmed acute TSCI, fulfilled all our inclusion criteria, and were included. A total of 316 (87.5\%) of them were originally admitted to the six hospitals that are licensed to provide care for patients with acute TSCI. Another 32 patients with TSCI who were hospitalised acutely elsewhere in Saint Petersburg were later transferred to one of these six hospitals after the diagnosis was clarified. In addition, 13 persons sustained a TSCI while somewhere outside of Saint Petersburg. They were initially admitted to hospitals in other regions of Russia and then transferred to one of the specialised hospitals in Saint Petersburg as soon as they could be safely transported.

In one of the hospitals, all data for 2012 were lost, while in another, data for the first half of 2012 were lost. Information regarding an estimated maximum of 30 patients from the year 2012 is therefore missing from our study. 
Table 1 Annual incidence rate of TSCI 2012-2016 per 1 million inhabitants, and distribution by sex and age

\begin{tabular}{llllll}
\hline & 2012 & 2013 & 2014 & 2015 & 2016 \\
\hline$N$ of cases & 53 & 91 & 79 & 78 & 60 \\
Incidence rate (per million) & 12.4 & 21.2 & 18.0 & 17.7 & 13.6 \\
Incidence rate by sex & & & & & \\
$\quad$ Male & 20.2 & 34.1 & 31.3 & 26.6 & 20.6 \\
$\quad$ Female & 6.3 & 10.8 & 7.4 & 10.6 & 8.1 \\
Incidence rate by age (years) & and sex & & & & \\
18-29 & & & & & \\
Total & 19.3 & 32.2 & 28.1 & 22.2 & 15.2 \\
$\quad$ Male & 33.9 & 54.9 & 39.7 & 32.5 & 28.1 \\
$\quad$ Female & 4.8 & 9.5 & 16.5 & 11.7 & 2.3 \\
30-44 & & & & & \\
Total & 13.6 & 15.0 & 22.5 & 17.0 & 12.4 \\
$\quad$ Male & 22.9 & 24.1 & 39.4 & 23.5 & 17.4 \\
Female & 4.7 & 6.2 & 6.1 & 10.7 & 7.6 \\
45-59 & & & & & \\
Total & 8.7 & 19.0 & 15.0 & 15.8 & 14.0 \\
Male & 8.6 & 31.8 & 29.1 & 26.8 & 18.7 \\
Female & 8.7 & 8.6 & 3.4 & 6.8 & 10.2 \\
$\geq 60$ & & & & & \\
Total & 7.8 & 15.5 & 6.8 & 13.5 & 11.0 \\
Male & 10.3 & 25.4 & 9.9 & 19.8 & 14.9 \\
Female & 6.6 & 10.5 & 5.2 & 10.3 & 9.0 \\
\hline & & & & &
\end{tabular}

\section{Incidence}

The annual incidence rate for 2012-2016 was 16.6 per 1 million adults (Table 1). Excluding the year 2012, for which data were incomplete, the incidence was 17.6 per million. The incidence for each year separately is shown in Table 1 .

\section{Sex, age, and employment}

Of the entire cohort, 256 (70.9\%) with TSCI were men, with male:female ratio of 2.4:1. The lowest proportion of women was identified in $2014(22.8 \%)$ and the highest in 2015 and 2016 (both 33.3\%). The mean (SD) age at injury was 42.1 (16.9) years, and the median (IQR) was 38.0 (27.0 to 55.0) years in the whole group (valid $n, 343$ ). The mean (SD) age of women was higher than for men (39.5 [14.8] vs. 48.7 [20.1] years). The age-related and sex-related distributions are shown in Fig. 1. A higher percentage of TSCI among men occurred at a young age, whereas among women, TSCI was equally frequent across all age groups. In total, $39.6 \%$ of the population with TSCI were employed at the time of their injury, whereas up to $32.4 \%$ were unemployed (Fig. 2).

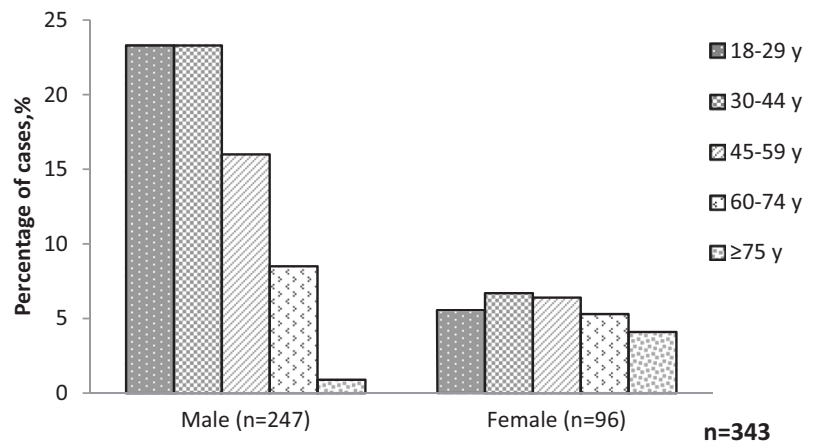

Fig. 1 Percent of cases distributed by age group and sex

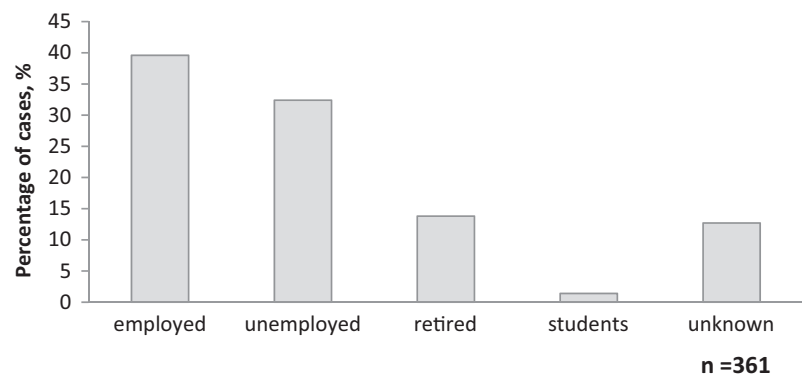

Fig. 2 Employment status at the time of TSCI

\section{Causes of TSCI}

The most frequent cause of TSCI was falls $(49.8 \%)$, followed by motor vehicle accidents (18.9\%) $(n=322$; Table 2). Falls from a height $(>1 \mathrm{~m})$ were registered in $33.9 \%$, whereas low falls were the cause in $15.9 \%$. In the younger age groups ( $<60$ years), the leading cause was high falls, whereas in the elderly group ( $\geq 60$ years), it was low falls. The mean (SD) age for patients with falls from $<1 \mathrm{~m}$ was 53.9 (13.3) years. The male:female ratio in the low-falls group was 1.2:1, but this ratio shifted in the older age group ( $\geq 60$ years) to $0.5: 1$ (7 men, 14 women). Violence as a cause of TSCI was more common in the group that was documented as unemployed compared with those who were employed. The distribution of TSCI causes was similar across the whole registration period.

\section{Level and AIS grade of TSCI}

The injuries occurred at the cervical level in 178 (49.3\%) cases, thoracic level in 89 (24.7\%), lumbar/sacral level in 85 (23.5\%), and not classified in 9 (2.5\%). In total, 43 cases (11.9\%) of TSCI involved injuries at two or more levels based on magnetic resonance imaging findings.

From 319 charts with sufficient information on type of injury, number and percentage of TSCI patients according to level of injury and AIS grade are shown in Table 3. 
Table 2 Number and percentage of various TSCI causes by sex and age

\begin{tabular}{|c|c|c|c|c|c|c|c|c|c|c|c|c|c|c|}
\hline & & \multicolumn{10}{|c|}{ Age-group (years) } & \multirow{2}{*}{\multicolumn{2}{|c|}{ Total (by sex) }} & \multirow[t]{3}{*}{ Total $^{2}$} \\
\hline & & \multicolumn{2}{|c|}{$18-29$} & \multicolumn{2}{|c|}{$30-44$} & \multicolumn{2}{|c|}{$45-59$} & \multicolumn{2}{|c|}{$60-74$} & \multicolumn{2}{|l|}{$\geq 75$} & & & \\
\hline \multicolumn{2}{|l|}{ Sex } & M & $\mathrm{F}$ & M & $\mathrm{F}$ & M & $\mathrm{F}$ & M & $\mathrm{F}$ & M & $\mathrm{F}$ & M & $\mathrm{F}$ & \\
\hline \multirow[t]{16}{*}{ Cause } & High falls & 29 & 6 & 23 & 6 & 26 & 7 & 7 & 2 & 1 & 2 & 86 & 23 & 109 \\
\hline & & 12.5 & 6.7 & 9.9 & 6.7 & 11.2 & 7.8 & 3 & 2.2 & 0.4 & 2.2 & 37.1 & 25.6 & 33.9 \\
\hline & Low falls & 2 & 1 & 6 & 5 & 13 & 3 & 6 & 9 & 1 & 5 & 28 & 23 & 51 \\
\hline & & 0.9 & 1.1 & 2.6 & 5.6 & 5.6 & 3.3 & 2.6 & 10 & 0.4 & 5.6 & 12.1 & 25.6 & 15.9 \\
\hline & MVA & 11 & 6 & 16 & 6 & 5 & 8 & 5 & 3 & 0 & 1 & 37 & 24 & 61 \\
\hline & & 4.7 & 6.7 & 6.9 & 6.7 & 2.2 & 8.9 & 2.2 & 3.3 & 0 & 1.1 & 15.9 & 26.7 & 18.9 \\
\hline & Sport & 6 & 1 & 4 & 1 & 0 & 0 & 0 & 0 & 0 & 0 & 10 & 2 & 12 \\
\hline & & 2.6 & 1.1 & 1.7 & 1.1 & 0 & 0 & 0 & 0 & 0 & 0 & 4.3 & 2.2 & 3.7 \\
\hline & Diving & 10 & 1 & 7 & 0 & 0 & 0 & 1 & 0 & 0 & 0 & 18 & 1 & 19 \\
\hline & & 4.3 & 1.1 & 3 & 0 & 0 & 0 & 0.4 & 0 & 0 & 0 & 7.8 & 1.1 & 5.9 \\
\hline & Violence & 2 & 1 & 12 & 1 & 3 & 0 & 1 & 0 & 0 & 0 & 18 & 2 & 20 \\
\hline & & 0.9 & 1.1 & 5.2 & 1.1 & 1.3 & 0 & 0.4 & 0 & 0 & 0 & 7.8 & 2.2 & 6.2 \\
\hline & Other & 8 & 0 & 2 & 0 & 3 & 2 & 3 & 2 & 0 & 1 & 16 & 5 & 21 \\
\hline & & 3.4 & 0 & 0.9 & 0 & 1.3 & 2.2 & 1.3 & 2.2 & 0 & 1.1 & 6.9 & 5.5 & 6.5 \\
\hline & Unknown & 4 & 2 & 5 & 1 & 4 & 2 & 5 & 1 & 1 & 4 & 19 & 10 & 29 \\
\hline & & 1.7 & 2.2 & 2.2 & 1.1 & 1.7 & 2.2 & 2.2 & 1.1 & 0.4 & 4.4 & 8.2 & 11.1 & 9 \\
\hline \multirow[t]{2}{*}{ Total } & & 72 & 18 & 75 & 20 & 54 & 22 & 28 & 17 & 3 & 13 & 232 & 90 & 322 \\
\hline & & 31 & 20 & 32.3 & 22.2 & 23.3 & 24.4 & 12.1 & 18.9 & 1.3 & 14.4 & 100 & 100 & 100 \\
\hline
\end{tabular}

$M$ male, $F$ female, $M V A$ motor vehicle accidents

${ }^{\mathrm{a}} n=322$

\section{Variations in TSCl incidence by month and weekday}

Occurrence of TSCI was highest in July and August and lowest in March and December (Fig. 3). It occurred most frequently on Saturdays and Sundays and least frequently on Thursdays (Fig. 3).

\section{Acute surgical treatment}

Acute surgical treatment was administered in 238 (74.1\%) of the TSCI patients (321 charts contained information). In 97 cases $(30.2 \%)$, surgery was performed during the first 24 $\mathrm{h}$, and after $24 \mathrm{~h}$ in 141 cases (43.9\%), but usually in the first few days (median [IQR], 4 (2 to 7) days; range, 22; mode, 2 days). A total of 83 patients (25.9\%) did not have surgery.

\section{Alcohol and drug consumption before trauma}

Among the 160 cases with specific information available in the charts, 108 had no intake of alcohol during $24 \mathrm{~h}$ before the injury. In 48 cases (13.3\%), intake of alcohol was recorded (35 men, 13 women), and alcohol intake was equally common in women and men. The proportion of patients with recorded alcohol intake remained stable through the registration period. Intake of alcohol was recorded in $75.0 \%$ of unemployed persons, which was higher than among those who were employed, retired, or students (16.7\%, 8.3\%, and 0\%, respectively). Four persons (1.1\%) with TSCI reported taking illegal drugs before the injury.

\section{Concomitant injuries}

Additional injuries were observed in 163 TSCI cases (47.2\%) (data were available in 345 cases). Traumatic brain injuries occurred in $130(37.7 \%)$ and injuries outside the central nervous system in 112 cases (32.5\%). A total of 79 $(60.8 \%)$ patients with concomitant brain injury also had non-neurological lesions.

\section{Discussion}

We found an annual TSCI incidence of 17.6 per million people in Saint Petersburg for the period 2013-2016. The data for 2012 were not reliable (because of missed cases), whereas the low incidence of TSCI in 2016 reflected the downward trend of TSCI in Saint Petersburg. No previous studies are available from this or similar areas, and different regions of Russia probably have variable incidences and 
causes of TSCI. Indeed, historical data from other parts of Russia indicate higher incidences [12-14].

Our study was carried out in an urban, well-developed area with a political and social environment that has changed during the last 30 years. The lower incidence of TSCI than previously reported in Russia may be explained by increased awareness of possible risk factors and introduced preventive measures, and also by more reliable methodology. Schedrenok and coworkers reported a higher incidence of motor-vehicle related injuries [13]. Our study revealed that falls represent the main cause of TSCI. The effects of laws regulating seatbelt use and allowable alcohol level

Table 3 Number and percentage of TSCI patients according to spinal cord level and AIS grade

\begin{tabular}{|c|c|c|c|}
\hline Spinal cord level & AIS grade & $N$ & $\%$ \\
\hline \multirow[t]{5}{*}{$\mathrm{C} 1-4$} & AIS A & 6 & 1.7 \\
\hline & AIS B & 8 & 2.2 \\
\hline & AIS C & 9 & 2.5 \\
\hline & AIS D & 22 & 6.1 \\
\hline & Unknown AIS & 4 & 1.1 \\
\hline \multirow[t]{5}{*}{ C5-8 } & AIS A & 14 & 3.9 \\
\hline & AIS B & 14 & 3.9 \\
\hline & AIS C & 21 & 5.8 \\
\hline & AIS D & 39 & 10.8 \\
\hline & Unknown AIS & 9 & 2.5 \\
\hline \multirow[t]{5}{*}{ Unspecified C } & AIS A & 4 & 1,1 \\
\hline & AIS B & 0 & 0,0 \\
\hline & AIS C & 6 & 1,7 \\
\hline & AIS D & 16 & 4,4 \\
\hline & Unknown AIS & 6 & 1,7 \\
\hline \multirow[t]{5}{*}{ Th1-S5 } & AIS A & 30 & 8.3 \\
\hline & AIS B & 29 & 8.0 \\
\hline & AIS C & 25 & 6.9 \\
\hline & AIS D & 76 & 21.1 \\
\hline & Unknown AIS & 14 & 3.9 \\
\hline Unknown & & 9 & 2.5 \\
\hline Total & & 361 & 100 \\
\hline
\end{tabular}

while driving are probably reflected in our results. We also believe the following changes implemented in recent years probably affected our findings:

- Installation of video cameras along roads to record violations of traffic rules, permission to punish drivers based on data from these video cameras, and improved driver training combined with more demanding tests for a driver's license [19].

- Implementation of a car recycling program to activate the process of replacing old cars with new ones, and introduction of new tax rates for old cars [20].

- Adding penalties for the use of a mobile phone without a hands-free device during the vehicle's movement and for an unfastened seatbelt [21].

- Strengthening the requirements for driving schools [22].

- Penalties for driving in a state of intoxication, with a criminal punishment for a repeated offence [23].

The number of motor vehicle accidents in Russia decreased from 233,809 in 2007 to 173,700 in 2016 [24].

Studies from neighbouring countries have reported different TSCI incidences [1, 25]. Scandinavia has the lowest TSCI incidence [25]. A retrospective hospital-based study in Denmark (1990-2012) revealed the average incidence of TSCI to be 10.2 per million [4], whereas a register-based survey in Finland (1976-2005) showed an incidence of 13.8 per million [9]. A study from China (2004-2008), which neighbours the Asian part of Russia, revealed a considerably higher incidence of 23.7 per million [26]. Our study demonstrates figures similar to those of other European countries [11, 27, 28], probably reflecting a similar lifestyle in Saint Petersburg, the fourth largest city in Europe, compared with other urban areas on the continent.

TSCI was more common in men than in women (ratio 2.4:1), similar to previous studies [1, 25]. However, the prevalence among men was even more pronounced in a study from Norway (ratio 4.7:1) [11]. Of interest, our study revealed a considerable difference in age distribution between the sexes, with men sustaining their TSCI at a
Fig. 3 Percentage of TSCI occurring by day of the week and month of the year

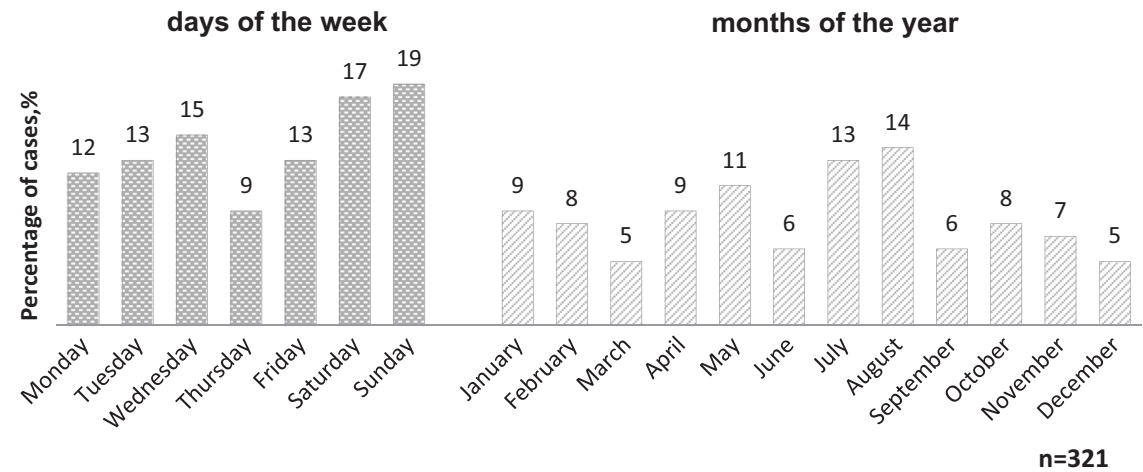


younger age. Men tend to engage in a more risky lifestyle (sports, crime) and consume more alcohol than women. Falls from a height in young age often result from professional activities in which men are overrepresented. Women outlive men and are more likely to have spinal fractures with TSCI due to osteoporosis. Similar findings have been reported in a previous study from Norway [11]. With a mean age of 42.1 years, we showed that TSCI is not a condition that predominantly occurs at young age.

Among our patients, upto $32.4 \%$ were unemployed at the time of the injury, while the percentage of unemployed people in Saint Petersburg was on average $19.1 \%$ in the same period [15]. Violence as a cause of TSCI was higher among the unemployed persons, and unemployment seems to be a factor in the incidence of TSCI. Unemployment similarly emerged as a risk factor in a study from China, where TSCI patients had a high rate of unemployment [3].

Alcohol intake is a risk factor for TSCI [7, 29]. In our study, alcohol intake prior to TSCI was documented in only $13.3 \%$ of cases, however, and the reported use of illegal drugs was rare. The patient charts probably underrepresent such risk factors because medical personnel did not systematically ask about or test for intake of alcohol or illegal drugs. Patient information may also have been unreliable. Our study indicates an effect of lifestyle factors such as alcohol and unemployment, but prospective studies are needed to determine their precise effects.

An awareness of TSCI causes is necessary for better prevention. Despite ongoing measures aimed at protecting the life and health of Russian citizens, such as the Federal Law "Technical Regulations on the Safety of Buildings and Structures" [30], the frequency of TSCI from falls is still high. Most falls occurred from a level higher than $1 \mathrm{~m}$. However, low falls occurred more often in older age, and women were overrepresented in this group.

We observed that falls and motor vehicle accidents were the main causes of TSCI. Preventive measures should continue to be a focus, including traffic safety and fall prevention in workplaces and at home. Our study demonstrated that nearly one half of persons with TSCI had multiple injuries. Multiple injuries make acute surgery, as well as rehabilitation more complicated and prolonged. Traumatic brain injuries were especially common, occurring in $37.7 \%$. However, this rate is lower than previously reported [31, 32].

In $16.9 \%$ of cases, a complete TSCI was found, and it occurs in a minority of cases throughout the world $[3,6,10$, 11]. One half of the injuries were at the cervical level, and most of them were incomplete. The injuries at the cervical level may need respiratory follow-up, as well as extensive rehabilitation with involvement of several specialties. Therefore, the investigation of the frequency, level, and severity of TSCI is important for the organisation of proper medical care for TSCI patients.
Our study indicates a higher frequency of spinal cord injuries in summer, particularly in July and August. Weekends also represent a period of high TSCI frequency. A previous study from Russia found the same pattern [14]. The results strongly indicate that people are prone to TSCI during leisure time, probably in association with a lifestyle involving more frequent use of alcohol and drugs, as well as more demanding physical activities. Occurrence by seasons and weekdays has rarely been examined previously [33, 34].

Our study had some limitations. Those who died at the prehospital stage, as well as those who were injured outside the city but never brought back to Saint Petersburg (because of discharge or death), were not included. The year 2012 had some missing patient files, and some included cases had incomplete data. These gaps may have led to an underestimation of some TSCI factors and to inaccuracies in assessing TSCI associations. The official population data from the Saint Petersburg area represent an underestimation because of immigrants and other persons with no records in official registries. According to unofficial data, the number of migrants in Saint Petersburg ranges from 500,000 to $1,000,000$, whereas according to official data, the number is about 250,000. Immigration makes estimation of incidence imprecise, although we excluded everyone without an official Saint Petersburg registration. Persons under age 18 years were not included either; however, the annual incidence of TSCI among children in Saint Petersburg was estimated to be 8-10 per million in 2012-2016 (Vissarionov $\mathrm{SV}$, personal communication, unpublished).

\section{Conclusions}

The annual incidence of TSCI in Saint Petersburg was 17.6 per million during 2013-2016. The incidence decreased during the observation period and is now similar to that of other European countries. Falls and motor vehicle accidents were the main causes of TSCI, and there was a high occurrence of multiple injuries, including brain injuries. One half suffered from TSCI at the cervical level, and most TSCIs were incomplete. Mean age at the time of injury was 42.1 years, and $70.9 \%$ of the injuries occurred in men. Women sustained TSCI at an older age. Unemployment was a factor in increased risk for TSCI, and leisure activities in summer and weekends represent possible risk factors for TSCI. Preventive measures for the identified risk factors are the key to further reducing TSCI incidence in Saint Petersburg.

\section{Data archiving}

The data sets generated and analysed during the current study are available from the corresponding author on request. 
Acknowledgements We express our personal gratitude to A. Dulaev, A. Sarana, T. Skoromets, V. Dorofeev, S. Petrov, Y. Linets, G. Sokurenko, and V. Rybnikov for their help in finding medical records. We thank statistician O. Klicenko, PhD in Saint Petersburg and statistician G.E. Eide for help and guidance. We are very grateful to N. Tcinzerling for assistance in organising the study.

Author contributions LM was responsible for searching for and collecting data and for statistical analysis, references, and preparation and revision of the manuscript. NEG was responsible for preparation and revision of the manuscript, evaluation of methods, and approval of the final version. SL was responsible for the design, organisation, and management of the research and editing and approval of the final version. TR was responsible for study design, creating the tables and figures, interpreting the results, the literature search, and preparation and revision of the manuscript.

Funding The study was supported by a grant from the Norwegian Centre for International Cooperation in Education.

\section{Compliance with ethical standards}

Conflict of interest The authors declare that they have no conflict of interest.

Ethical statement The study was approved by the Research Ethics Committee of the North-Western State Medical University, named after I.I. Mechnikov, Saint Petersburg, Russia (No 10/date 09.11.2016)

Publisher's note: Springer Nature remains neutral with regard to jurisdictional claims in published maps and institutional affiliations.

\section{References}

1. Hagen EM, Rekand T, Gilhus NE, Grønning M. Traumatic spinal cord injuries-incidence, mechanisms and course. Tidsskr Nor Laege. 2012;132:831-7.

2. Cripps RA, Lee BB, Wing P, Weerts E, Mackay J, Brown D. A global map for traumatic spinal cord injury epidemiology: towards a living data repository for injury prevention. Spinal Cord. 2011;49:493-501.

3. Feng H-Y, Ning G-Z, Feng S-Q, Yu T-Q, Zhou H-X. Epidemiological profile of 239 traumatic spinal cord injury cases over a period of 12 years in Tianjin, China. J Spinal Cord Med. 2011;34:388-94.

4. Bjørnshave Noe B, Mikkelsen EM, Hansen RM, Thygesen M, Hagen EM. Incidence of traumatic spinal cord injury in Denmark, 1990-2012: a hospital-based study. Spinal Cord. 2015;53:436-40.

5. Wyndaele M, Wyndaele J-J. Incidence, prevalence and epidemiology of spinal cord injury: what learns a worldwide literature survey? Spinal Cord. 2006;44:523-9.

6. Ning G-Z, Wu Q, Li Y-L, Feng S-Q. Epidemiology of traumatic spinal cord injury in Asia: a systematic review. J Spinal Cord Med. 2012;35:229-39.

7. Sabre L, Pedai G, Rekand T, Asser T. Linnamägi ü, Kõrv J. High incidence of traumatic spinal cord injury in Estonia. Spinal Cord. 2012;50:755-9.

8. Juocevicius A, Jamontaite IE, Adomaviciene A. People with spinal cord injury in Lithuania. Am J Phys Med Rehabil. 2017;96: S86-9.
9. Ahoniemi E, Alaranta H, Hokkinen E-M, Valtonen K, Kautiainen $\mathrm{H}$. Incidence of traumatic spinal cord injuries in Finland over a 30-year period. Spinal Cord. 2008;46:781-4.

10. Koskinen EA, Alen M, Väärälä EM, Rellman J, Kallinen M, Vainionpää A. Centralized spinal cord injury care in Finland: unveiling the hidden incidence of traumatic injuries. Spinal Cord. 2014;52:779-84.

11. Hagen EM, Eide GE, Rekand T, Gilhus NE, Gronning M. A 50-year follow-up of the incidence of traumatic spinal cord injuries in Western Norway. Spinal Cord. 2010;48:313-8.

12. Silberstein B, Rabinovich S. Epidemiology of spinal cord injuries in Novosibirsk, Russia. Spinal Cord. 1995;33:322-5.

13. Schedrenok V, Orlov S, Anikeev N, Krasnoshlyk P, Sovakov I, Moguchaya O. Epidemiology and quality of medical aid in combined column-spinal cord trauma in some regions of Russion Federation [in Russian]. Neurochir [Russ]. 2010;11:458-66.

14. Shcherbuk Y, Bagnenko A, Dulaev A, Dulaeva N, Alikov Z. Organization of specialized medical care to patients with urgent surgical pathology of the spine [In Russian]. Hir Pozvonoc. 2011; 2:67-73.

15. Federal State Statistics Service. http://petrostat.gks.ru. Accessed on 4 May 2018.

16. Kraus JF, Franti CE, Riggins RS, Richards D, Borhani NO. Incidence of traumatic spinal cord lesions. J Chronic Dis. 1975; 28:471-92.

17. Kirshblum SC, Burns SP, Biering-Sorensen F, Donovan W, Graves DE, Jha A, et al. International standards for neurological classification of spinal cord injury (revised 2011). J Spinal Cord Med. 2011;34:535-46.

18. Biering-Sørensen F, DeVivo MJ, Charlifue S, Chen Y, New PW, Noonan $\mathrm{V}$, et al. International spinal cord injury core data set (version 2.0) -including standardization of reporting. Spinal Cord. 2017;55:759-64.

19. Decree of the Russian Federation Government. The Federal program "Improving road safety in 2006-2012". 100 Feb 20, 2006. http://docs.cntd.ru/document

20. Order of the Ministry of Industry and Trade of the Russian Federation. On approval of the strategy for the development of the automobile industry of the Russian Federation for the period to 2020. 319 Apr 23, 2010. http://legalacts.ru

21. Federal Law №196. The Code of the Russian Federation on Administrative Offenses. Jul 23, 2013. http://koapkodeksrf.ru

22. Decree of the Russian Federation Government. The federal program "Improving road safety in 2013-2020". 864 Oct 3, 2013. http://docs.cntd.ru/document

23. Federal Law №528. The Criminal Code of the Russian Federation Dec 31, 2014. http://legalacts.ru

24. The number of traffic accidents in Russia. http://statistika.ru/tra nsport, Accessed on 5 May 2018.

25. Chiu W-T, Lin H-C, Lam C, Chu S-F, Chiang Y-H, Tsai S-H. Review paper: epidemiology of traumatic spinal cord injury: comparisons between developed and developing countries. Asia Pac J Public Health. 2010;22:9-18.

26. Ning G-Z, Yu T-Q, Feng S-Q, Zhou X-H, Ban D-X, Liu Y, et al. Epidemiology of traumatic spinal cord injury in Tianjin, China. Spinal Cord. 2011;49:386-90.

27. Ferro S, Cecconi L, Bonavita J, Pagliacci MC, Biggeri A, Franceschini M. Incidence of traumatic spinal cord injury in Italy during 2013-2014: a population-based study. Spinal Cord. 2017;55:1103-7.

28. McCaughey EJ, Purcell M, McLean AN, Fraser MH, Bewick A, Borotkanics RJ, et al. Changing demographics of spinal cord injury over a 20-year period: a longitudinal population-based study in Scotland. Spinal Cord. 2016;54:270-6.

29. Barinov A, Kondakov E. Clinical and statistical characteristics of acute spine and spinal cord injury [In Russian]. Hir Pozvonoc [Russ]. 2010;4:15-8. 
30. Federal Law of the Russian Federation. Technical regulations on the safety of buildings and structures. 384 Dec 30, 2009. http:// legalacts.ru

31. Bombardier CH, Lee DC, Tan DL, Barber JK, Hoffman JM. Comorbid traumatic brain injury and spinal cord injury: screening validity and effect on outcomes. Arch Phys Med Rehabil. 2016; 97:1628-34.

32. Hagen EM, Eide GE, Rekand T, Gilhus NE, Gronning M. Traumatic spinal cord injury and concomitant brain injury: a cohort study: Traumatic spinal cord injury and concomitant brain injury. Acta Neurol Scand. 2010;122:51-7.

33. Yang S, Ding W, Yang D, Gu T, Zhang F, Zhang D, et al. Epidemiology and risk factors of cervical spine injury during heating season in the patients with cervical trauma: a cross-sectional study. Nishiura H PLoS ONE 2013;8:e78358.

34. Anghelescu A. Prevention of diving-induced spinal cord injuriespreliminary results of the first Romanian mass media prophylactic educational intervention. Spinal Cord Ser Cases. 2017;3:17018. 